\title{
PROPERTY RISK UNDER SOLVENCY II: EFFECTS OF DIFFERENT UNSMOOTHING TECHNIQUES
}

\author{
Pablo DURÁN SANTOMIL ${ }^{1 *}$, Luís OTERO GONZÁLEZ ${ }^{2}$, \\ Onofre MARTORELL CUNILL ${ }^{3}$, Anna M. GIL-LAFUENTE ${ }^{4}$ \\ ${ }^{1}$ Department of Business Organization and Marketing, University of Santiago de Compostela, \\ Avda. de Afonso X O Sabio, s/n. 27002 Lugo, Spain \\ ${ }^{2}$ Department of Finance and Accounting, University of Santiago de Compostela, \\ Avda. do Burgo, s/n. 15782 Santiago de Compostela, Spain \\ ${ }^{3}$ Department of Business Economics, University of the Balearic Islands, \\ C/de Valldemosa Km 7,5, Campus UIB, 07122 Balearic Islands, Spain \\ ${ }^{4}$ Department of Economics and Business, University of Barcelona, \\ Av. Diagonal 690, 08034 Barcelona, Spain
}

Received 30 October 2017; accepted 02 Septemeber 2018

\begin{abstract}
Solvency II imposes risk-based capital requirements on EU insurance companies. This paper evaluates the property risk standard model proposed. The calibration was performed from the IPD UK monthly index total returns for the period between December 1986 and December 2009. In general, it is considered that returns derived from valuation-based indices are smoother than those derived from transaction-based indices. This paper contributes to the existing literature by applying various unsmoothing techniques to this index. The results show that the capital requirements, applying the same calculation method (historical value at risk at the $99.5 \%$ confidence level) as in the calibration of the standard model, are generally bigger than those proposed in the standard model of Solvency II.
\end{abstract}

Keywords: Solvency II, internal model, standard model, property risk, QIS5, unsmoothing returns, IPD UK index.

JEL Classification: D81, G22.

\section{Introduction}

Solvency II reviews the rules for assessing the financial situation of European insurance companies, with the aim of ensuring that companies have risk-adjusted capital levels. Under the new regulation, economic or risk-based capital may be calculated using either the standard formula or an internal model validated by supervisory authorities. In both cases,

*Corresponding author. E-mail: pablo.duran@usc.es

This is an Open Access article distributed under the terms of the Creative Commons Attribution License (http://creativecommons. org/licenses/by/4.0/), which permits unrestricted use, distribution, and reproduction in any medium, provided the original author and source are credited. 
the amount of capital is obtained through the value at risk (VaR) with a confidence level of 99.5\%. Solvency II also allows the possibility of replacing predefined parameters with company risk parameters that are more appropriate for the firm's own risk profile (Butaci, Dzitac, Dzitac, \& Bologa, 2017). One important factor of Solvency II is that it employs market values to assess the available capital, which could overstate the companies' balance sheet exposure to short-term market volatility, creating a disincentive for investment in illiquid, long-term, risky assets such as property (BlackRock, 2012; Hoering, 2013; Focarelli, 2017).

The insurance sector is the largest institutional investor in Europe, with an investment portfolio of almost $€ 9,800$ bn (nearly $3 \%$ of the total portfolio) in property assets other than those for its own use (Insurance Europe, 2016). Hoesli, Lekander, and Witkiewicz (2004) found that real estate is an effective portfolio diversifier in mixed-asset portfolios. There is an increasing literature investigating how the new regulation of Solvency II can affect the portfolio of insurers. Gatzert and Martin (2012) showed that the asset allocation of an insurance company strongly influences the risk-based capital under Solvency II and pointed out that model risk may be an important issue, so model choice and calibration play an important role in the quantification. Hoering (2013) compared the capital charge of the standard model with the capital charge of the S\&P rating model, investigating whether the investment portfolios of insurance companies will be reshaped within the new framework. Braun, Schmeiser, and Schreiber (2017) optimized a life insurance company's asset allocation in the context of the market risk capital requirements of Solvency II. However, literature that focuses on property risk models under Solvency II is very scarce (Investment Property Databank [IPD], 2011; Schlumpf, Tessera, \& Martínez, 2013). Besides, the data on direct real estate returns are very poor; therefore, it is difficult to estimate the market risk (Schlumpf et al., 2013).

This paper evaluates the proposed standard model in Solvency II for property risk. The calibration of property risk was made using the fifth Quantitative Impact Study (QIS5) from the IPD monthly index of the UK for the period between December 1986 and December 2009 (CEIOPS, 2010b). A historical VaR is calculated at the $99.5 \%$ level of confidence for the smoothed empirical annual returns. In general, it is considered that the income from valuation-based indexes, such as the IPD, is more smoothed than that arising from transaction-based indexes. This smoothing causes time series to be less volatile and therefore underestimates the actual variation experienced by the market. This paper contributes to the literature by applying various techniques of unsmoothing to the IPD UK Index. The methodology used in this paper is likely to be replicated by the insurance industry to build internal models that assess their level of risk exposure and requirements of capital needs under the new regulation.

The work is divided into four sections. In the first section, we describe how the property risk sub-module has been calibrated and the stress scenarios imposed on the insurance industry by the EIOPA, previously named the CEIOPS. In the second section, we analyse the smoothing causes of the real estate indexes based on appraisals, while the third section presents different techniques for desmoothing. In the fourth section, we conduct an empirical analysis of the IPD monthly index of the UK ${ }^{1}$ for the time period between 1987 and 2010 and for the series that result from applying different unsmoothing methods. Finally, the main conclusions are presented.

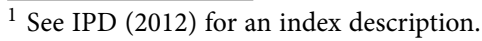




\section{Measuring property risk in Solvency II}

The European Commission (EC) has requested the CEIOPS to acquire insights into the possible quantitative impacts of this new Solvency standard through a series of quantitative impact studies (Steffen, 2008). In QIS5 (see Committee of European Insurance and Occupational Pensions Supervisors [CEIOPS], 2010a, 2010b), the capital charge for property risk was based on the calculation of a stress scenario in which the shock was the effect of a $25 \%$ drop in the value of all direct and indirect individual exposures to property prices. Thus, property risk arose from the variability of the market prices of real estate. Risk calibration was performed only from the monthly IPD index of the UK for the period between December 1986 and December 2009. The historical VaR was calculated at the confidence level of $99.5 \%$ for the annual empirical returns, so no parametric distribution was assumed. Annual returns were calculated from monthly returns through a 12-month rolling window. The unsmoothing return was not available, so they worked with the smoothed index data. It was also assumed, in light of the analysed data, that there were no significant differences between the index of all properties and the different sub-indices.

European Insurance and Occupational Pensions Authority [EIOPA] (2011a) summarized the results achieved by the European insurance industry in QIS5. On average $12 \%$ of the total market SCR (14\% in insurance groups) was caused by property risk, but there were big differences depending on each company. Although the standard model for this risk was not one of the most criticized by the industry itself, it was mentioned that this module was not being developed enough, because it did not consider the location of the property or its use, providing capital charges that were too high, and that the calibration was inadequate for longterm guarantees backed by long-term assets. In 2011 a report commissioned from the IPD by associations of real estate and insurance sectors was published, focusing on the analysis of risk in direct investment in property in Solvency II (IPD, 2011). The most important criticism was that the calculation of the capital requirements for real estate in QIS5 was less robust than in previous studies. It was argued that the data were limited to the UK market, which is statistically much more volatile than the major European markets in which insurers have most of their exposures. Furthermore, in QIS5 the application of an unsmoothing technique to the returns was rejected. Thus, in this report a quarterly pan-European index is compiled from the IPD data, including 15 countries for the years 1999-2009, from which the VaR is estimated. The results show that the capital charge would be $7.1 \%$ for the IPD index based on appraisals and $13.3 \%$ for the unsmoothed index. Based on these results, it is recommended that the capital charge finally used in the standard model of Solvency II does not exceed 15\%. The EIOPA replaced the CEIOPS on 1 January 2011. The most recent studies by the EIOPA concerned so-called long-term guarantees (LTGA) (EIOPA, 2013a, 2013b). They provided a package of measures (counter-cyclical premium, matching adjustment, transitional measures, etc.) with the goal that insurance companies with long-term products are not as penalized as in previous studies. In addition to the six quantitative impact studies for insurance companies, another study on pension funds was carried out in 2012 (EIOPA, 2012). None of these impact studies made a new calibration of the property risk.

Finally, we note that the EIOPA conducted stress tests to obtain information on the vulnerability of the European insurance sector to adverse scenarios. The stress scenarios were 
considered in line with the macroeconomic assumptions that apply stress testing in the banking sector, although they were adapted to the specificities of the insurance business. In 2011 three stress scenarios were established: base (severe), adverse (more severe deterioration in macroeconomic variables) and inflation (a rapid increase in inflation that forces the European Central Bank/ECB to raise interest rates quickly). Focusing on the risk associated with properties, the separation between commercial and residential investment was highlighted, which did not occur in the different QISs. For residential risk the ECB provided assumptions about the change in housing prices. For commercial investment the fall in the IPD index for the UK in 2008 was regarded as the adverse scenario. Based on this a shock of $25 \%$ in the adverse scenario and $12.5 \%$ in the baseline scenario was assumed. In 2014 the EIOPA, in cooperation with the ESRB (European Systemic Risk Board) (EIOPA, 2014), designed two adverse financial market scenarios for the 2014 EIOPA stress test. In adverse stress scenario number 1 , the stress impacts were a downward shock of $49 \%$ for commercial property and $17 \%$ for residential property. In scenario number 2 , a downward shock of $18 \%$ for commercial property and 15\% for residential property was assumed. In 2016 the EIOPA launched a new stress test exercise in which property scenarios were provided by the ESRB and ECB (European Central Bank) staff and were complemented by the EIOPA. Property shocks were defined on the country level, and again differentiation was made for commercial and residential property (EIOPA, 2016).

\section{Cause of the smoothed indexes based on appraisals}

There are basically three methods for measuring the performance of commercial real estate assets: indices based on appraisals, repeat sales indexes and indexes based on the hedonic price (see Booth \& Marcato, 2004). Indexes based on appraisals use data from the assessments made periodically by appraisers. Repeat sales indexes use data recorded for properties that have been sold at least twice within the study period. Often only a small percentage of properties meet the above criteria, but the weighted repeat sales method or regression method of repeat sales can use a much larger sample of the properties that have been transmitted at least twice during the measurement of the total period (from the beginning to the end of the index construction, not necessarily between two calculation dates). In the hedonic price method, multivariate regression is performed of the elements that influence the value of a property, so its price is modelled, which is called the hedonic price, depending on such characteristics. It is possible to produce an index of the price of a property that holds the standard features. Finally a hybrid method or a combination of the above techniques may be performed.

The best-known and most-used commercial real estate performance rates are the IPD index (Investment Property Databank index) in the UK, which is also available for other countries, and the NPI (NCREIF Property Index) in the US (also called simply NCREIF - National Council of Real Estate Investment Fiduciaries), both based on appraisals. They are calculated by aggregating the performance of individual commercial properties from institutional investors (insurance companies, pension funds and investment funds). The returns from indices based on appraisal are smoother than those derived from transactions or operations based 
on buying and selling operations. Appraisers usually perform the valuation of a property at the end of a period (year, semester, quarter or month depending on the index); thus, they are aware of the results of the previous valuation. This often leads to autocorrelation and creates more minor volatility than in the indexes based on transactions (see the evidence in Fisher, Miles, \& Webb, 1999; Fisher, Gatzlaff, Geltner, \& Haurin, 2003). This effect is known as smoothing, and different unsmoothing techniques have been developed that can be used to develop series that represent the underlying price more accurately.

The smoothed indices based on appraisals are produced mainly by the process of individual assessment of the properties and by the process of aggregation of individual valuations in the index (see Blundell \& Ward, 1987; Quan \& Quigley, 1989, 1991; Geltner, 1991, 1993a, 1993b; Fisher, Geltner, \& Webb, 1994; Brown \& Matysiak, 1998, 2000; Cho, Kawaguchi, \& Shilling, 2003; Key \& Marcato, 2007). At the individual level, it is said that the process of real estate appraisal is retrospective and based on comparables, causing smoothing. Given the low liquidity level of real estate markets, there is little comparable information for new reassessments, especially those undertaken in short periods (for example monthly or quarterly). An appraiser who has not received sufficient new evidence to make a new estimate of the value usually refers to the latest appraisal value. It is also likely that more major difficulties will arise in explaining large changes in values than in explaining smaller changes. Finally, valuations may be anchored further to their last value so that an appraiser does not report any change in the valuation until a certain limit (for example a change of $1 \%$ of the property value) is exceeded. Thus, appraisers show conservative behaviour and value properties by adjusting the precedent values, so they do not fully incorporate the observed movements in the market ${ }^{2}$.

Blundell and Ward (1987) in the UK and Quan and Quigley $(1989,1991)$ in the US were the first to suggest that each evaluation can be considered as a weighted average of the last valuation and new market evidence:

$$
V_{t}=(1-k) P_{t}+k V_{t-1},
$$

where $V_{t}$ is the current valuation issued by the appraiser; $P_{t}$ the estimated market price based on the current situation (most recent transaction prices); $P_{t-1}$ the last valuation made and $\mathrm{k}$ a weighting coefficient with a value between 0 and 1 .

A value of $k=0$ would be a valuation based totally on the current evidence of the market, meaning that the appraised value would be very close to the real one. A value of $k=1$ would result in the same valuation as carried out in the previous period. When there is greater uncertainty (more volatile environments), an appraiser is likely to put more emphasis on the previous values. This assessment process has been documented empirically by authors such as Diaz III and Wolverton (1998) and Clayton, Geltner, and Hamilton (2001). This retrospective procedure is seen as an optimal strategy given the uncertainty of the property market and does not imply incompetence (Quan \& Quigley, 1991; Brown \& Matysiak, 2000). However, the problem arises that appraisers can be influenced externally, mainly by their clients, when markets are down, which could result in additional smoothing. Baum, Crosby,

\footnotetext{
2 However, authors like Lai and Wang (1998) question the premises on which the smoothing explanation is based (lack of confidence, moving-average appraisals, reliance on past information and temporary aggregation).
} 
McAllister, Gallimore, and Gray (2000) explored the potential influences of customers on individual assessments.

The process of aggregation of individual valuations in the index causes smoothing even though individual appraisals represent the true market values. The valuations of the individual properties are taken as estimates of market prices, which change over time due to changes in the market. The value of an index at a specific time point, for example at the end of a month, is based on the assessments made for a short period of time prior to that date. Thus, the index valuations are a smoothed moving average of the observations for a short period of time (Geltner, 1993a). It is also possible that different appraisers show different reaction speeds to new market evidence (Brown \& Matysiak, 2000).

While smoothing is theoretically caused by the individual assessment process and the aggregation process, returns of indices have three characteristics based on empirical assessments that confirm that they are smoothed (Corgel \& DeRoss, 1999; Key \& Marcato, 2007):

- They show positive serial correlation, so high and low returns tend to persist from one period to another.

- They have very low volatility relative to other risk assets, including securities of real estate companies. Furthermore, they are not correlated with the returns of the values of such companies.

- Models of efficient portfolios produce allocations that far exceed those observed in the investment portfolios of the real world.

\section{Unsmoothing techniques}

In the literature various techniques have been developed to unsmooth returns (known as recovery models) and to obtain a new set of returns that has been adjusted to eliminate the behaviour of appraisers and therefore attain more volatile results. The general model is given by Corgel and DeRoss (1999):

$$
r_{t}^{*}=\omega_{0} r_{t}+\omega(B) r_{t-1}^{*},
$$

where $r_{t}^{*}$ is the performance of the observed index or is smoothed over period $\mathrm{t} ; r_{t}$ is the true value or unsmoothed value during period t; $\omega_{0}$ is a weight between 0 and 1 , and $\omega(B)=\omega_{1}+\omega_{2} B+\omega_{3} B^{2}+\cdots, B$ being the lag operator.

We can express $r_{t}^{*}$ in terms of the past and present values of $r_{t-1}^{*}$ :

$$
r_{t}^{*}=\phi(B) r_{t-1}^{*}+\varepsilon_{t}
$$

where $\phi(B)=\phi_{1}+\phi_{2} B+\phi_{3} B^{2}+\ldots$ is the polynomial operator of delays and $\varepsilon_{t}=\omega_{0} r_{t}$, where $\omega_{0}$ represents the so-called unsmoothing factor.

Thus, the residual term $\varepsilon_{t}$ contains the unsmoothing performance and the smoothing effect of valuations. The term $\phi(B) r_{t-1}^{*}$ captures the effect on the average of previous returns on the current performance. Finally, unsmoothed returns are given by:

$$
r_{t}=\frac{\left(r_{t}^{*}-\phi(B) r_{t-1}^{*}\right)}{\omega_{0}} .
$$


Different models assume different hypotheses within this general model. The most frequently used models in the literature are those by Geltner (1993a) and Fisher et al. (1994), but we also analyse the so-called autoregressive filter of $n$ order, the model of Chaplin (1997) and the model of Brown and Matysiak (1998). The analysis does not attempt to provide a comprehensive review of the existing methods in the literature but uses those analysed by Key and Marcato (2007).

The Geltner (1993a) model or autoregressive filter of order 1 is derived directly from the assessment process of Quan and Quigley (1991). Given the assessment made by appraisers $V_{t}=(1-k) P_{t}+k V_{t-1}$, the market price can be obtained as $P_{t}=\left(V_{t}-k V_{t-1}\right) /(1-k)$ and therefore the unsmoothed returns of an index as:

$$
r_{t}=\frac{\left(r_{t}^{*}-k r_{t-1}^{*}\right)}{1-k}
$$

where $k$ is the first-order autoregressive parameter of the series of observed or smoothed returns $r_{t}^{*}$.

Geltner's (1993a) method is applied to annual data and corrects the first-order serial correlation to the performance from one period to the next. In higher-frequency indexes it is reasonable to expect that the links between the current and the previous valuation date back more than one period. A more generalized version is to apply an autoregressive filter of $n$ order from which unsmoothed returns can be obtained as:

$$
r_{t}=\frac{\left(r_{t}^{*}-k_{1} r_{t-1}^{*}-k_{2} r_{t-2}^{*}-\ldots-k_{n} r_{t-n}^{*}\right)}{1-k_{1}-k_{2}-\ldots-k_{n}} .
$$

Autoregressive parameters $\left(k_{i}\right.$ for $\left.i=1, \ldots, n\right)$ can be estimated empirically from observed data $r_{t}^{*}$. To determine the proper delay, significant coefficients are selected based on the associated $t$ statistic, the explanatory power of the model $\left(\mathrm{R}^{2}\right)$ and/or traditional model selection criteria based on the likelihood function (the BIC, AIC or Hannan-Quinn information criterion).

Fisher et al. (1994) proposed a model that incorporates the relationship between the volatility of equities $\left(\rho_{S P 500}\right.$ or the standard deviation of the Standard \& Poor's 500 stock index, when it is applied to the American market) and the true volatility of returns $\left(\sigma_{r_{t}}\right)$ so that the former is twice the latter $\left(\sigma_{r_{t}}=\sigma_{S P 500} / 2\right)$. Unsmoothing returns are often estimated from:

$$
r_{t}=\frac{\left(r_{t}^{*}-\left(k_{1} r_{t-1}^{*}+k_{4} r_{t-4}^{*}\right)\right)}{\omega_{0}} .
$$

The fourth-order lagged value $\left(r_{t-4}^{*}\right)$ is included to reflect the fact that there are properties in the NPI index that are effectively revalued only annually, which happens in the fourth quarter of the year. The value $\omega_{0}$ is calculated from $\omega_{0}=2 \sigma\left[r_{t}^{*}-\left(k_{1} r_{t-1}^{*}+k_{4} r_{t-4}^{*}\right)\right] / \sigma_{S P 500}=$ $2 \sigma_{\varepsilon_{t}} / \sigma_{S P 500}$, where $\sigma_{\varepsilon_{t}}$ is the standard deviation of the residuals of the autoregressive model, which are a proxy for the deviation of unsmoothed returns. This model could be used by applying a first-order autoregressive filter if the autoregressive parameter $k_{4}$ is not significant. In this case $r_{t}=\left(r_{t}^{*}-k_{1} r_{t-1}^{*}\right) / \omega_{0}$ with $\omega_{0}=2 \sigma_{\varepsilon_{t}} / \sigma_{S P 500}$. As observed, $\omega_{0}$ takes a value inferior to 1 when the volatility of the equity index is more than twice the volatility of the perfor- 
mance of the unsmoothed returns, resulting in a further increase in the volatility of the final unsmoothed returns. When the volatility of the equity index is less than twice the performance of the unsmoothed values, $\omega_{0}$ takes a value greater than 1 and dampens the volatility of the final values of the unsmoothed returns. The value assigned (equal to 2) to the relation between the volatility of property returns and the stock market is a matter of judgement. An alternative specification to the volatility condition is to set the value of $\omega_{0}$ in such a way that the mean of the unsmoothed series equals that of the smoothed series $\left(\omega_{0} \mid E\left(r_{t}\right)=E\left(r_{t}^{*}\right)\right)^{3}$.

The method of different market conditions, proposed by Chaplin (1997), assumes different rates of the smoothing parameter $k_{i}$ depending on the market situation. It is assumed that indices are more smoothed when high rates of appreciation or depreciation occur in the market, because the evidence or information provided by the market is less true in periods of rapid changes in prices than in those markets that are more stable. In addition, the smoothing effects are more likely to be strong in declining markets than in rising ones, as appraisers are more reluctant to lower valuations than to enlarge them. Therefore, the model results in:

$$
r_{t}=\left(r_{t}^{*}-k_{i} r_{t-1}^{*}\right) /\left(1-k_{i}\right)
$$

where the $k_{i}$ unsmoothing ratio varies around a base value resulting from the autoregressive method of order 1, it being common to apply the following procedure (see Key \& Marcato, 2007) $)^{4}$.

The method of Brown and Matysiak (1998) allows the magnitude of the effects of smoothing on the returns to vary. Unlike Chaplin's (1997) model, in which these are produced according to the so-called states of the market, it is performed through the serial correlation changes observed during the different time periods. The Kalman filter is applied to estimate the unsmoothing coefficients, like the serial correlation coefficient observed in the original series $r_{t}^{*}$ over a preceding period. Thus, this method needs more observations than previous ones to produce a reasonably reliable estimate of the changes in the correlation of the number of returns, so it is more suitable for monthly or quarterly series than yearly ones. The model results in:

$$
r_{t}=\left(r_{t}^{*}-k_{t} r_{t-1}^{*}\right) /\left(1-k_{t}\right),
$$

where $k_{t}$ is an autoregressive parameter that varies over time, being calculated on a number of previous returns at every moment of time.

The unsmoothing techniques require several choices: the model to be used, the use of total returns or capital returns and finally the use of nominal or real returns. Regarding the model to be used, Brown and Matysiak (2000) claimed that despite the literature there is no superior method for unsmoothing a series of returns, although it seems that a smoothing

\footnotetext{
$\overline{3}$ This is always advisable, since the unsmoothing of a series should alter its volatility and autocorrelation but not its average value.

4 The greatest value that is added to the base value occurs in periods in which smoothed returns are more than \pm 2 standard deviations from the mean. Small additions or deductions are made in the base value for the periods with returns between 1 and 2 standard deviations from the mean or within 1 standard deviation of the mean. The size of the additions or deductions remains a matter of judgement provided that they add 0 or, which is the same, that the average value of $\mathrm{k}$ remains unchanged.
} 
series varies over time. Second, the returns series used may be total returns (capital returns plus rental returns) or only capital returns. The unsmoothing techniques can be applied to the total returns, but some authors have acknowledged that this problem can be more present in capital returns (Fisher et al., 1994). The third and final decision to make concerns the use of nominal returns or real returns (Fisher et al., 1994). When using this second option, the nominal returns become real returns subtracting the effect of inflation to apply the unsmoothing techniques subsequently. Finally, we would obtain nominal returns by adding inflation again.

\section{Empirical analysis of the smoothed and unsmoothed return series}

We employ data from the IPD Global UK monthly series (source: Thomson Reuters Datastream) for all properties for the period between 31 December 1986 and 31 December 2010. The similar pattern between the global index of all properties and its sub-indexes (IPD Industrial, IPD Offices and IPD Retail) is confirmed by the high correlation between the total arithmetic returns of the series over the time period analysed (coefficients ranging from 0.873 to 0.952 ). We have also proven that these coefficients are relatively stable and highly significant across different subsamples. We will focus our analysis on the monthly IPD All Properties index, like the analysis in QIS5. The temporal evolution of the total arithmetic returns of the IPD series (Figure 1 left) confirms the sharp crisis since mid-2007 and the market recovery starting in the middle of 2009. Figure 1 on the right shows the histogram, in which it can be seen that the distribution of monthly returns is asymmetric and has excess kurtosis.

Table 1 shows the summary statistics of the overall performance of the analysed monthly series, in which the excess kurtosis and rejection of the normality assumption measured by the Jarque-Bera test can be seen. The total returns are generated from the income returns and capital returns. The variability of the series of income returns $(0.09 \%)$ is much lower than that of the capital returns $(1.16 \%)$. The coefficient of the linear correlation between capital returns and income returns is close to zero and insignificant.
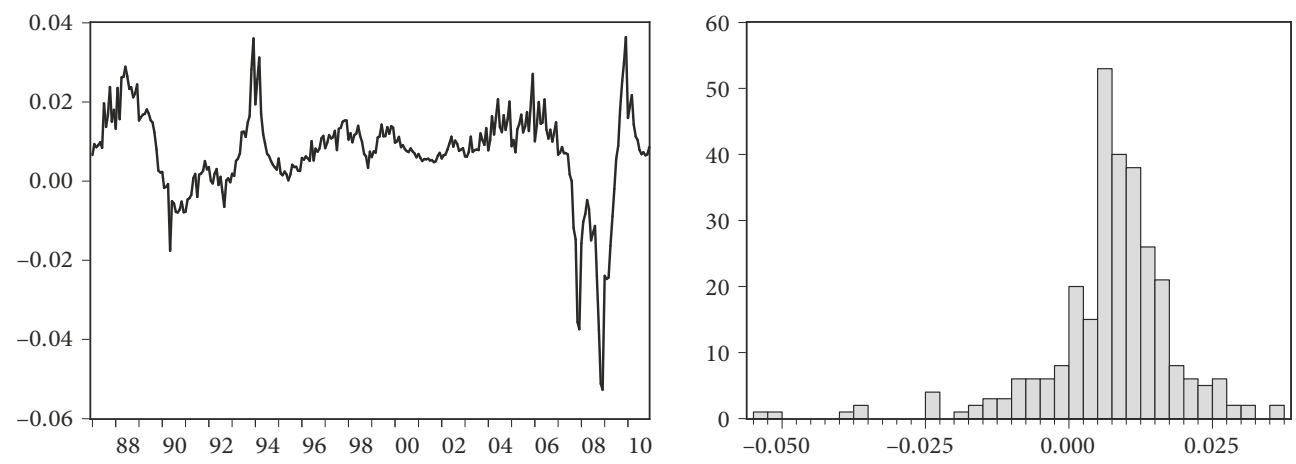

Figure 1. Temporal evolution of the returns of the IPD series and histogram (source: Prepared by the authors based on the IPD series, Thomson Reuters Datastream) 
Table 1 . Summary statistics

\begin{tabular}{|l|c|c|c|}
\hline \multicolumn{1}{|c|}{ Statistic } & Total return & Income return & Capital return \\
\hline Average & $0.72 \%$ & $0.58 \%$ & $0.14 \%$ \\
\hline Maximum & (December 2009) 3.64\% & $0.78 \%$ & $3.01 \%$ \\
\hline Minimum & (December 2008) -5.27\% & $0.39 \%$ & $-5.84 \%$ \\
\hline Standard deviation & $1.16 \%$ & $0.09 \%$ & $1.16 \%$ \\
\hline Skewness & -1.62 & -0.17 & -1.51 \\
\hline Kurtosis & 8.96 & 2.19 & 8.54 \\
\hline Jarque-Bera & 551.77 & 9.14 & 478.69 \\
\hline Probability & 0.00 & 0.01 & 0.00 \\
\hline
\end{tabular}

The literature assumes that real estate indices based on appraisals show a strong positive serial correlation. Figure 2 shows the total monthly returns of the IPD index for the 1987-2010 period compared with its preceding period. If these returns were not correlated, the graphic would show points with a purely random nature and the regression line would be flat (the slope equals zero). The positive slope (value of 0.90 ) indicates a positive association between returns throughout successive periods. The goodness of fit measured by the adjusted determination coefficient $\mathrm{R}^{2}(0.82)$ is high.

We compute the autocorrelation function (ACF) and partial autocorrelation function (PACF) of the total returns. We observe a strong linear autocorrelation structure. We can say that the returns depend strongly and persistently on the previous returns, with a linear autocorrelation coefficient of the first order equal to 0.903 , while the coefficient for 12 delays is 0.174 . The autocorrelation characteristics of the global return series are not generated by the low variability of the series of income returns, but the results obtained when analysing the capital returns are very similar (the coefficients are 0.905 and 0.180 , respectively).

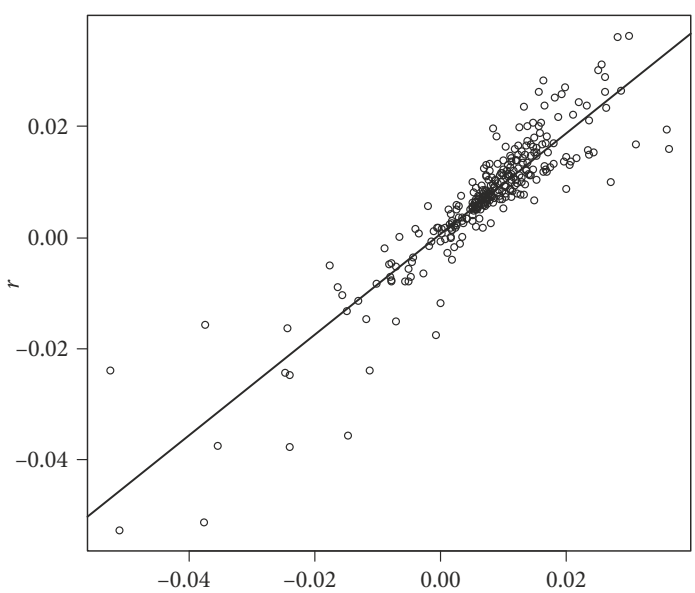

Figure 2. Regression of the total monthly returns of the IPD index (1987-2010) and its preceding period 
We proceed to apply the unsmoothing techniques described above to the series of nominal total returns of the IPD index, because this series is used in the analysis of the QIS5 calibration and in the report by the IPD (2011). The assumptions and calculations required in the estimation of the models are:

- For the method of Gelter (1993a), the only parameter to estimate is the coefficient AR (1) of the smoothed returns. The estimated value is 0.90 .

- For the autoregressive model of $n$ order, we test different models with multiple orders. Models different from an AR (1) model result in no significant parameters and do not exceed the above based on the model selection criteria, so this model is excluded from the analysis.

- For the model of Fisher et al. (1994), we use the AR (1) base model, because the parameter $k_{4}$ associated with $r_{t-4}^{*}$ is not significant. Within this model we establish two alternatives to the value of $w_{0}$. The first takes the value $\omega_{0}=2 \sigma_{\varepsilon_{t}} / \sigma_{F T S E}$ based on the ratio between the standard deviation of unsmoothed returns and that of an equity market index (FTSE index). The estimated values are $\sigma_{\varepsilon_{t}}=0.49 \%$ and $\sigma_{F T S E}=$ $4.13 \%$, resulting in a value of $\omega_{0}=0.24$. The second, $\omega_{0} \mid E\left(r_{t}\right)_{t}=E\left(r_{t}^{*}\right)$, uses the hypothesis of equality of means between the unsmoothed series and the original series (smoothed). As a result of applying this method, the following proportion is obtained, $\omega_{0}=0,81 \sigma_{\varepsilon_{t}} / \sigma_{F T S E}$, resulting in a value of $\omega_{0}=0.10$. Therefore, the application of this second method will result in a further increase in the volatility of the final unsmoothed returns.

- For the method of Brown and Matysiak (1998), the parameters of the unsmoothing values are set from the autoregressive parameters calculated for each period over the preceding 36 months by a Kalman filter. In addition, to test the sensitivity of the previous model, we carry out estimations on 24,48 and 60 previous months. The values of the autoregressive parameters estimated on the basis of 36 and 60 months can be seen in Figure 3. In the case of the model estimated over 36 months (solid line), it mainly highlights the sharp fall in the serial correlation from levels around 0.88 (mid-2002) to a minimum of 0.07 (February 2007), from which date it experienced a rapid increase to return to levels around 0.9 (early 2009), thereafter remaining relatively stable. The other two serial correlation drops occurred from the middle of 1991 (values around 0.95) until early 1993 (around 0.53) and from March 1998 (0.86) to June 1999 (0.61). In the model estimated over 60 months (dashed line), the falls in the desmoothing parameter are dampened; however, we can say that the unsmoothing parameter again seems to vary over time.

- For the method of Chaplin (1997), additions to/deductions from the value provided by the AR (1) parameter $(k=0.90)$ are applied subjectively based on the relationship between the smoothed returns and their distance in standard deviations $\left(\sigma_{r_{t}^{*}}\right)$ from the average $\left(\mu_{r_{t}^{*}}\right)$. Given the high base value (0.90), not many differences between the unsmoothing parameters in each market state (see Table 2) are established. The parameters are used to keep the average of the unsmoothed series similar to that of the original one; however, they are not free from value judgements. 


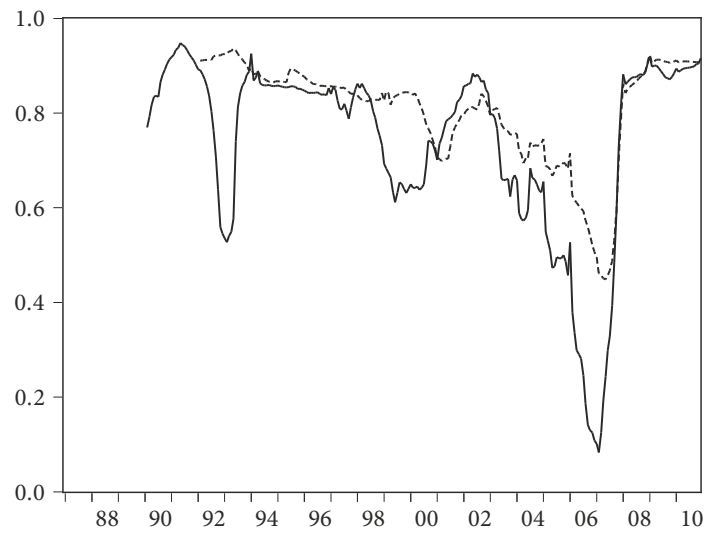

Figure 3. Autoregressive parameters estimated using a Kalman filter on the basis of 36 and 60 months

Table 2. Additions to/deductions from the base value in Chaplin's method

\begin{tabular}{|c|c|c|c|}
\hline$k_{i}$ & Market states & Return hypothesis & Additions/Deductions \\
\hline 0.92 & $r_{t}^{*}>3.0 \%$ & $r_{i}>\mu_{r_{t}^{*}}+2 \sigma_{r_{t}^{*}}$ & +0.02 \\
\hline 0.89 & $3.0 \% \leq r_{t}^{*}>1.9 \%$ & $\mu_{r_{t}^{*}}+2 \sigma_{r_{t}^{*}} \leq r_{i}>\mu_{r_{t}^{*}}+1 \sigma_{r_{t}^{*}}$ & -0.01 \\
\hline 0.87 & $1.9 \% \leq r_{t}^{*}>0.7 \%$ & $\mu_{r_{t}^{*}}+1 \sigma_{r_{t}^{*}} \leq r_{i}>\mu_{r_{t}^{*}}$ & -0.03 \\
\hline 0.88 & $0.7 \% \leq r_{t}^{*}>-0.4 \%$ & $\mu_{r_{t}^{*}} \leq r_{i}>\mu_{r_{t}^{*}}-1 \sigma_{r_{t}^{*}}$ & -0.02 \\
\hline 0.91 & $-0.4 \% \leq r_{t}^{*}>-1.6 \%$ & $\mu_{r_{t}^{*}}-1 \sigma_{r_{t}^{*}} \leq r_{i}>\mu_{r_{t}^{*}}-2 \sigma_{r_{t}^{*}}$ & 0.01 \\
\hline 0.93 & $r_{t}^{*} \leq-1.6 \%$ & $r_{i} \leq \mu_{r_{t}^{*}}-2 \sigma_{r_{t}^{*}}$ & 0.03 \\
\hline
\end{tabular}

Table 3 shows the results of the original series of the IPD and the unsmoothed series using the exposed methods. The methods of Geltner (1993a), Chaplin (1997) and Brown and Matysiak (1998) (calculating over the base in a moving window of 36 months) obtain values for the monthly average similar to the original average $(0.72 \%)$, which is a desirable feature. Fisher's et al. (1994) model, based on the ratio between the deviation of the unsmoothed returns and the equity market returns (original version), attains lower values, but the problem is corrected in the second version. All the discussed methods raise the monthly volatility of the original series (1.16\%). Geltner's model (1993a) multiplies it by 4.4 times, the model of Fisher et al. (1994) in its original version by 1.8 times and in its amended version by 4.4 times and the model of Chaplin (1997) by 6 times, while the Brown and Matysiak (1998) model multiplies it by 3.5 times (36-month version). In the case of analysing the annual volatility, the discussed methods also increase the volatility of the original series although by a smaller quantity, whether by calculating natural years (the end of December each year) or whether by calculating the annual returns based on a 12-month moving window. The analysed methods 


\begin{tabular}{|c|c|c|c|c|c|c|c|c|c|}
\hline 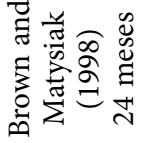 & $\frac{\circ}{\stackrel{0}{n}}$ & $\begin{array}{l}\stackrel{\circ}{4} \\
\stackrel{+}{+}\end{array}$ & $\begin{array}{l}\frac{0}{3} \\
i n \\
i n\end{array}$ & $\frac{\partial}{m}$ & $\begin{array}{l}\text { ○े } \\
\text { o } \\
\text { ذ̇ }\end{array}$ & 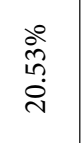 & 的 & $\begin{array}{c}\overrightarrow{1} \\
\overrightarrow{0}\end{array}$ & $\begin{array}{l}\stackrel{0}{\infty} \\
\infty \\
+ \\
\infty \\
i \\
1\end{array}$ \\
\hline 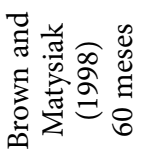 & ڤे & $\stackrel{\partial}{\stackrel{\oplus}{+}}$ & $\begin{array}{l}\text { oे } \\
\text { فे } \\
\text { aे }\end{array}$ & $\begin{array}{l}\stackrel{0}{\infty} \\
\stackrel{\infty}{\Xi} \\
=\end{array}$ & $\begin{array}{l}\stackrel{0}{+} \\
\stackrel{0}{0} \\
\stackrel{\infty}{\rightarrow}\end{array}$ & $\begin{array}{l}\stackrel{0}{\infty} \\
\stackrel{\text { }}{+} \\
\stackrel{m}{m}\end{array}$ & $\stackrel{0}{\circ}$ & $\begin{array}{l}\stackrel{0}{0} \\
\stackrel{0}{1}\end{array}$ & $\begin{array}{l}\stackrel{0}{0} \\
\text { Oें } \\
\stackrel{\oplus}{1}\end{array}$ \\
\hline 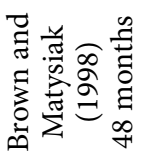 & $\begin{array}{l}\stackrel{0}{0} \\
\infty \\
\dot{0}\end{array}$ & $\begin{array}{l}\stackrel{\text { ปे }}{0} \\
\stackrel{+}{+}\end{array}$ & $\begin{array}{l}\stackrel{0}{ } \\
\text { ळे }\end{array}$ & 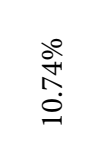 & 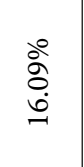 & $\begin{array}{l}\stackrel{0}{ } \\
\text { in } \\
\infty \\
0 \\
0\end{array}$ & $\stackrel{\text { Lִ }}{0}$ & $\begin{array}{l}0 \\
\stackrel{0}{0} \\
1\end{array}$ & $\begin{array}{l}\stackrel{0}{\oplus} \\
\stackrel{p}{1}\end{array}$ \\
\hline 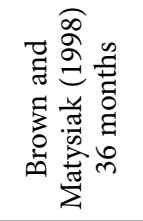 & $\stackrel{\stackrel{0}{N}}{\stackrel{0}{\circ}}$ & $\begin{array}{l}\stackrel{0}{ } \\
\text { Oे } \\
\text { +i }\end{array}$ & 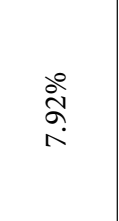 & $\frac{\partial}{\not{7}}$ & 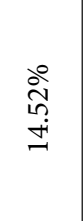 & $\begin{array}{l}\stackrel{2}{\circ} \\
\text { ఏें } \\
\text { থे }\end{array}$ & $\stackrel{8}{0}$ & 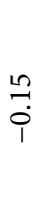 & 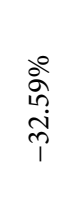 \\
\hline$\frac{\Xi}{\text { 节 }}$ & $\stackrel{\circ}{\stackrel{0}{\circ}}$ & $\begin{array}{l}\stackrel{0}{\circ} \\
\text { oे }\end{array}$ & $\begin{array}{l}\frac{0}{n} \\
\infty \\
\infty\end{array}$ & $\begin{array}{l}\stackrel{0}{ } \\
\infty \\
\stackrel{m}{n} \\
\stackrel{n}{n}\end{array}$ & 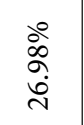 & 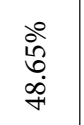 & $\begin{array}{l}m \\
0 \\
0\end{array}$ & $\begin{array}{l}0 \\
\stackrel{0}{0} \\
\dot{1}\end{array}$ & $\begin{array}{l}0 \\
\infty \\
\infty \\
\dot{10} \\
1\end{array}$ \\
\hline 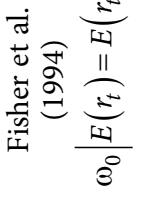 & $\stackrel{\stackrel{\circ}{N}}{\circ}$ & $\stackrel{\partial}{\stackrel{\partial}{F}}$ & $\frac{\partial}{\sigma}$ & $\begin{array}{l}\stackrel{0}{\infty} \\
\stackrel{\text { }}{=}\end{array}$ & 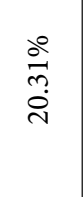 & 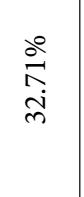 & $\begin{array}{l}\text { on } \\
\stackrel{0}{i}\end{array}$ & $\begin{array}{l}\text { J } \\
\dot{i}\end{array}$ & 辛 \\
\hline 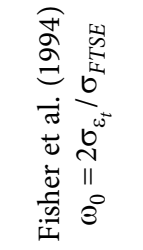 & $\begin{array}{l}\text { ঐे } \\
\text { ণे }\end{array}$ & $\begin{array}{l}\stackrel{0}{0} \\
\text { ¿े } \\
\text { ì }\end{array}$ & $\begin{array}{l}\stackrel{\circ}{\stackrel{9}{*}} \\
\stackrel{n}{4}\end{array}$ & $\frac{\partial}{\sigma}$ & 六 & $\begin{array}{l}\stackrel{2}{\curvearrowright} \\
\stackrel{=}{=}\end{array}$ & $\begin{array}{l}\text { on } \\
\dot{i}\end{array}$ & $\begin{array}{l}\text { J } \\
0\end{array}$ & 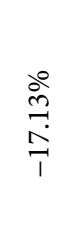 \\
\hline$\frac{\vec{\Xi}}{\stackrel{\Xi}{ \pm}}$ & 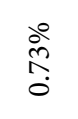 & $\begin{array}{l}\stackrel{0}{b} \\
\stackrel{-1}{\text { in }}\end{array}$ & $\begin{array}{l}\stackrel{0}{ } \\
\text { ळे } \\
\infty\end{array}$ & $\begin{array}{l}\stackrel{\circ}{\mid} \\
\stackrel{n}{=} \\
=\end{array}$ & 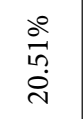 & $\begin{array}{l}\stackrel{0}{ } \\
\infty \\
\circ \\
\text { ले }\end{array}$ & $\begin{array}{l}0 \\
0 \\
0\end{array}$ & $\begin{array}{l}\text { J } \\
\dot{0}\end{array}$ & $\begin{array}{l}\stackrel{0}{0} \\
\stackrel{5}{+} \\
\stackrel{+}{+}\end{array}$ \\
\hline 㝵 & $\stackrel{\stackrel{\circ}{N}}{\stackrel{0}{0}}$ & $\begin{array}{l}\stackrel{8}{0} \\
\stackrel{-1}{\leftrightarrows}\end{array}$ & $\begin{array}{l}\stackrel{\circ}{\stackrel{+}{+}} \\
\stackrel{0}{\circ}\end{array}$ & $\begin{array}{l}\stackrel{\circ}{\stackrel{8}{*}} \\
\stackrel{5}{\circ}\end{array}$ & $\begin{array}{l}\stackrel{8}{\varrho} \\
\stackrel{\Xi}{=}\end{array}$ & $\begin{array}{l}\stackrel{\circ}{\dagger} \\
\stackrel{+}{=}\end{array}$ & @̊ & $\begin{array}{l}\infty \\
0 \\
0\end{array}$ & 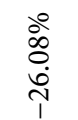 \\
\hline 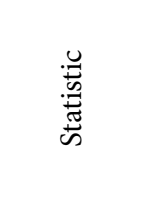 & 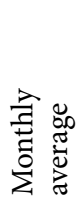 & 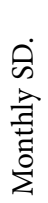 & 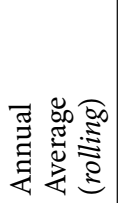 & 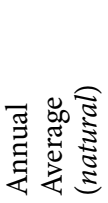 & 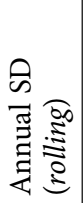 & 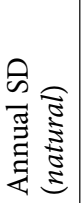 & $\bar{a}$ & $\tilde{Q}$ & 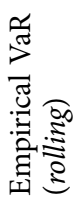 \\
\hline
\end{tabular}


eliminate the high autocorrelation of the original series. The serial correlation coefficients of orders 1 and 2, which are not significant for the tested models, are shown in the table below. In addition, under all of the unsmoothing models, the normality assumption for monthly and annual returns (based on the natural year and moving window) is rejected, which also happens with the original IPD series.

Finally the relevant calculation of $\mathrm{VaR}$, which reproduces the methodology used in the QIS5 calibration, is shown. For this, the $0.5 \%$ percentile is calculated, which represents the left tail of the empirical distribution of the calculated annual return based on a 12-month moving window. The different models provide different capital charges, which, except for the original model of Fisher et al. (1994), exceed those established in the standard model (25\%). The capital charge without unsmoothing the IPD index is $26.08 \%$, which is very similar to the standard model. The models can be divided into four main groups. The first group consists of the original model of Fisher et al. (1994), which provides a VaR of 17.13\%. The explanation for this reduced load comes from the volatility of the proxy used for unsmoothed returns $2 \sigma_{\varepsilon_{t}}$ turning out to be much lower than that of $\sigma_{F T S E}$ for the analysed period, so the value of 2 assigned to the relationship between volatilities seems to be inappropriate. The second group consists of Brown and Matysiak's model (1998) in their 36-, 48- and 60-month versions, which provide capital charges of around $33 \%$. The estimation of this model based on a 24-month window provides highly volatile autoregressive parameters, producing results that are not very reliable. The third group contains Geltner's (1993a) pattern and the model of Fisher et al. (1994) using the hypothesis of equality means between the original and the unsmoothed series. Both models provide capital charges of around $40 \%$ of the investment value. Finally, the last group consists of Chaplin's (1997) model, which obtains a very high capital charge; this in turn is not surprising given the subjectivity of the model, reaching very different values from different assumptions. Finally, we note that the empirical distribution of the returns on which the VaR is calculated using the method set by the CEIOPS/EIOPA is very irregular over time. Thus, if the technique was used until 2007, and therefore older and more recent market declines were excluded, it would obtain a historical VaR of $7.82 \%$ for the original IPD index.

\section{Conclusions}

Under the new solvency regulation for insurance companies, Solvency II, capital requirements can be determined using a standard model or internal models previously approved by the regulator. The property risk is based on the analysis of the monthly series of global returns for the IPD UK index for all properties (calibrated in QIS5). The use of valuationbased indexes, such as IPD UK, may underestimate the tail of the loss distribution (extreme outcomes) (e.g. Key \& Marcato, 2007). Therefore, in this paper we analysed different unsmoothing techniques for this index and assessed the capital needs resulting from their application compared with the standard model. We used monthly data on the IPD series, as the CEIOPS/EIOPA used in the standard model. It was observed that the capital charges obtained from these models are greater, generally, than those of the standard model (25\%). The original model of Fisher et al. (1994) provides a VaR (99.5\%) of 17.13\%, although the 
relation "by 2" between the volatility of equities and the real volatility of commercial returns seems to be unreasonable. Brown and Matysiak's (1998) model, in their versions of 36, 48 and 60 months, provide capital charges of around 33\%. The 24-month calculated version provides higher charges (38\%), although this method results in unsmoothing parameters that are too volatile to be considered. The models of Geltner (1993a) and Fisher et al. (1994), which use the hypothesis of equality of means between the unsmoothed series and the original series, obtain capital charges of around 40\%. Finally Chaplin's model (1997) obtains a very high capital charge, although the parameters used seem to indicate that it is not a very good model for the series.

We would like to highlight that there are several important aspects of the risk analysis of real estate that have not been addressed in this paper or in the actual standard model by the EIOPA/CEIOPS, proposing as future research a sensitivity study of the results obtained by analysing the effect of income returns' unsmoothing and the use of data in real terms; extending the analysis to markets outside the UK; a detailed analysis of the correlation with other market risks; the use of indexes not based on appraisal values; the distinction between direct/indirect investment and between commercial and residential property shocks defined on the country level (like the stress test scenarios of the EIOPA, 2016); and finally the possible use of different models to estimate VaR (value at risk).

Some of these aspects aspects have been addressed mainly in the studies of IPD (2011), Arias, Maury, and Foulquier (2017) and MSCI (2017).

It seems appropriate to ponder some of the above-mentioned aspects. The problems involved in measuring risk in markets outside the UK come from the lack of data, due to the lower frequency and the absence in many markets of long time series data enabling the reliable estimation of the $0.5 \%$ percentile. As recommended by the IPD (2011), the use of a global index or at least a pan-European one should be considered in the risk model of Solvency II. This will probably lead to lower capital charges than those currently considered in the standard model. As part of the post-evaluation of the new insurance supervisory regime, EIOPA has launched a project dedicated to the review of the Solvency Capital Requirement (SCR) standard formula. To provide new evidence to support an SCR for real estate that more accurately reflects the volatility of real estate investment in Europe, IPD-MSCI published an update of the 2011 study (MSCI, 2017). This new study support that UK property market is more volatile than other European property markets.

The analysis of the correlation with other market risks is again a difficult task given the limited market data, so, as stated by the IPD (2011) and Arias, Maury, and Foulquier (2017), the stipulated correlations in QIS5 are considered by European insurers as being too conservative (high). Another important issue, which was already used in the IPD (2011), report, is the possible use of indexes that are not based on appraisal values. The methodology used in the study by the IPD (2011) could be used to calibrate the property risk. The LTI index (see Devaney \& Martinez, 2011) is not based on appraisals and therefore there is no need to apply the techniques discussed in this paper. However, it is very difficult to find indexes of this type in Europe. The updated study (MSCI, 2017) estimates real estate volatility for European markets using transaction linked indicator methods finding that capital charges resulting from transaction linked indicator are higher than those obtained from valuation based indexes. 
Another proposal is to evaluate the desirability of distinguishing between direct and indirect investment. Schlumpf et al. (2013) estimate the market risk of indirect real estate as a proxy for direct real estate in Solvency II. As performed in the 2011, 2014, 2016 and 2018 stress tests of the EIOPA (EIOPA, 2011b, 2014, 2016, 2018), insurance could calculate risk considering the separation between commercial and residential investment. In this sense it seems that companies require greater specificity of the standard model, as could be achieved using the Swiss solvency test. The Swiss model is more granular than the standard model for Solvency II, calculating the TVaR (Tail VaR) at the confidence level of 99\%. With regard to the risk of real estate investment, four factors are distinguished: two for direct and two for indirect investment (see FINMA, 2011).

Finally, we wish to comment on the use of parametric techniques for the VaR calculation. It is well known that real estate returns are not normal. Miles and McCue (1984), Myer and Webb (1994), Graff, Harrington, and Young (1997), Maitland-Smith and Brooks (1999) and Maurer, Reiner, and Sebastian (2004) provided evidence for different markets (America, Australia, Britain and Germany). The CEIOPS/EIOPA stated that the distributions of property returns are generally characterized by long left fat-tails and excess kurtosis, signifying disparity from normal distribution, so they used the empirical distribution of the returns in QIS5 to calculate the VaR. In this work we replicated their methodology. Other alternatives could use time series techniques to estimate value-at-risk models or employ other tail risk measure as Tail VaR (e.g., MSCI, 2017).

\section{References}

Arias, L., Maury, T. P., \& Foulquier, P. (2017). The impact of Solvency II prudential regulation on property financing in the insurance industry. Economic Research Centre and Financial Analysis and Accounting Research Centre.

Baum, A., Crosby, N., McAllister, P., Gallimore, P., \& Gray, A. (2000). The influence of valuers and valuations on the workings of the commercial property investment market. Royal Institution of Chartered Surveyors/Investment Property Forum, London.

BlackRock. (2012). Balacing risk, return and capital requirements; the effect of Solvency II on asset allocation and investment strategy. Economist Intelligence Unit.

Blundell, D. M., \& Ward, C. W. R. (1987). Property portfolio allocation: a multi-factor model. Journal of Development Studies, 4(2), 145-156. https://doi.org/10.1080/02640828708723929

Booth, P. M., \& Marcato, G. (2004). The measurement and modelling of commercial real estate performance. British Actuarial Journal, 10(1), 5-61. https://doi.org/10.1017/S1357321700004530

Braun, A., Schmeiser, H., \& Schreiber, F. (2017). Portfolio optimization under Solvency II: implicit constraints imposed by the market risk standard formula. The Journal of Risk and Insurance, 84(1), 177-207. https://doi.org/10.1111/jori.12077

Brown, G. R., \& Matysiak, G. A. (1998). Valuation smoothing without temporal aggregation. Journal of Property Research, 15(2), 89-103. https://doi.org/10.1080/095999198368419

Brown, G. R., \& Matysiak, G. A. (2000). Real estate investment. Prentice Hall.

Butaci, C., Dzitac, S., Dzitac, I., \& Bologa, G. (2017). Prudent decisions to estimate the risk of loss in insurance. Technological and Economic Development of Economy, 23(2), 428-440.

https://doi.org/10.3846/20294913.2017.1285365 
Committee of European Insurance and Occupational Pensions Supervisors. (2010a). QIS5 Technical Specifications. Retrieved from https://eiopa.europa.eu/publications/qis/insurance/insurance-quantitative-impact-study-5/technical-specifications

Committee of European Insurance and Occupational Pensions Supervisors. (2010b). Solvency II Calibration Paper (CEIOPS-SEC-40-10). Retrieved from https://eiopa.europa.eu/ceiops-archive/documents/advices/ceiops-calibration-paper-solvency-ii.pdf

Chaplin, R. (1997). Unsmoothing valuation-based indices using multiple regimes. Journal of Property Research, 14(3), 189-210. https://doi.org/10.1080/095999197368609

Cho, H., Kawaguchi, Y., \& Shilling, J. D. (2003). Unsmoothing commercial property returns: a revision to Fisher-Geltner-Webb's unsmoothing methodology. The Journal of Real Estate Finance and Economics, 27(3), 393-405. https://doi.org/10.1023/A:1025898325952

Clayton, J., Geltner, D. M, \& Hamilton, S. W. (2001). Smoothing in commercial property valuations: evidence from individual appraisals. Real Estate Economics, 29(3), 337-360. https://doi.org/10.1111/1080-8620.00014

Corgel, J., \& DeRoss, J. (1999). Recovery of real estate returns for portfolio allocations. Journal of Real Estate Finance and Economics, 18(3), 279-296. https://doi.org/10.1023/A:1007728900308

Devaney, S., \& Martinez, R. (2011). Transaction based indices for the UK commercial real estate market. Journal of Property Research, 28(4), 269-289. https://doi.org/10.1080/09599916.2011.601317

Diaz III, J., \& Wolverton, M. L. (1998). A longitudinal examination of the appraisal smoothing hypothesis. Real Estate Economics, 26(2), 349-358. https://doi.org/10.1111/1540-6229.00749

European Insurance and Occupational Pensions Authority. (2011a). EIOPA Report on the fifth Quantitative Impact Study (QIS5) for Solvency II (TFQIS5-11/001). Retrieved from https://eiopa.europa.eu/ publications/reports/qis5_report_final.pdf

European Insurance and Occupational Pensions Authority. (2011b). Specifications for the 2011 EU-wide stress test in the insurance sector (FS-11/012). Retrieved from https://eiopa.europa.eu/Publications/ Surveys/Stress-Test-Framework.pdf

European Insurance and Occupational Pensions Authority. (2012). Quantitative Impact Study (QIS) on Institutions for Occupational Retirement Provision (IORPs) - technical specifications (EIOPA-BOS-12/085). Retrieved from https://eiopa.europa.eu/Publications/QIS/COM-TS-adapted-_20121008_.doc

European Insurance and Occupational Pensions Authority. (2013a). Technical specification on the long term guarantee assessment (Part I, EIOPA/13/061). Retrieved from https://eiopa.europa.eu/Publications/QIS/A_-_Technical_Specification_on_the_Long_Term_Guarantee_Assessment_Part_I_pdf

European Insurance and Occupational Pensions Authority. (2013b). Technical specifications part II on the long-term guarantee assessment (EIOPA/12/307). Retrieved from https://eiopa.europa.eu/Publications/QIS/20130125_EIOPA_LTGA_Technical_Specifications_Part_II_final.pdf

European Insurance and Occupational Pensions Authority. (2014). EIOPA Stress Test 2014 (EIOPA-14-215). Retrieved from https://eiopa.europa.eu/Publications/Surveys/eiopa-14-215_ stress_test_2014_specifications.pdf

European Insurance and Occupational Pensions Authority. (2016). 2016 EIOPA insurance stress test report (EIOPA 16/302). Retrieved from https://eiopa.europa.eu/publications/surveys/eiopabos-16-302\%20insurance\%20stress\%20test\%202016\%20report.pdf

European Insurance and Occupational Pensions Authority. (2018). Insurance stress test 2018 technical specifications (EIOPA-BoS-18-189). Retrieved from https://eiopa.europa.eu/Publications/Surveys/ EIOPA-BOS-18-189_Technical\%20Specifications_v20180528_28_05.pdf

FINMA 2011. Guideline on the SST market risk standard model. Retrieved from http://www.finma.ch/e/ beaufsichtigte/versicherungen/schweizer-solvenztest/Pages/default.aspx. 
Fisher, J., Miles, M., \& Webb, R. B. (1999). How reliable are commercial property appraisals? Another look. Real Estate Finance, 16(3), 9-15.

Fisher, J., Gatzlaff, D., Geltner, D. M., \& Haurin, D. (2003). Controlling for the impact of variable liquidity in commercial real estate price indices. Real Estate Economics, 31(2), 269-303.

https://doi.org/10.1111/1540-6229.00066

Fisher, J. D., Geltner, D. M., \& Webb, R. B. (1994). Value indices of commercial real estate: a comparison of index construction methods. Journal of Real Estate Finance and Economics, 9(2), 137-164. https://doi.org/10.1007/BF01099972

Focarelli, D. (2017). Why insurance regulation is crucial for long-term investment and economic growth (Working Paper No. 1). Retrieved from https://www.ivass.it/pubblicazioni-e-statistiche/pubblicazioni/att-sem-conv/2017/conf-131407/SEP-12017-Focarelli.pdf

Gatzert, N., \& Martin, M. (2012). Quantifying credit and market risk under Solvency II: standard approach versus internal model. Insurance: Mathematics and Economics, 51(3), 649-666. https://doi.org/10.1016/j.insmatheco.2012.09.002

Geltner, D. M. (1991). Smoothing in appraisal-based returns. Journal of Real Estate Finance and Economics, 4(3), 327-345. https://doi.org/10.1007/BF00161933

Geltner, D. M. (1993a). Temporal aggregation in real estate return indices. Journal of the American Real Estate and Urban Economics Association, 21(2), 141-166. https://doi.org/10.1111/1540-6229.00605

Geltner, D. M. (1993b). Estimating market values from appraised values without assuming an efficient market. Journal of Real Estate Research, 8(3), 325-345.

Graff, R. A., Harrington, A., \& Young, M. S. (1997). The shape of Australian real estate return distributions and comparisons to the United States. Journal of Real Estate Research, 14(3), 291-308.

Hoering, D. (2013). Will Solvency II market risk requirements bite? The impact of Solvency II on insurers' asset allocation. The Geneva Papers on Risk and Insurance-Issues and Practice, 38(2), 250-273. https://doi.org/10.1057/gpp.2012.31

Hoesli, M., Lekander, J., \& Witkiewicz, W. (2004). International evidence on real estate as a portfolio diversifier. The Journal of Real Estate Research, 26(2), 161-206.

Insurance Europe. (2016). European insurance - key facts. Retrieved from https://www.insuranceeurope.eu/sites/default/files/attachments/European\%20Insurance\%20-\%20Key\%20Facts\%20-\%20 August\%202016.pdf

Investment Property Databank. (2011). The IPD Solvency II review. Informing a new regulatory framework for real estate. Retrieved from http://www.europeanrealestateforum.eu/wp-content/ uploads/2013/09/11-04-15-IPD-Solvency-II-Review.pdf

Investment Property Databank. (2012). IPD index guide. Edition six - January. Retrieved from http://ec.europa.eu/finance/consultations/2012/benchmarks/docs/contributions/individual-others/ ipd-annex1_en.pdf

Key, T., \& Marcato, G. (2007). Index smoothing and the volatility of UK commercial real estate. Report for the Investment Property Forum.

Lai, T. Y., \& Wang, K. (1998). Appraisal smoothing: the other side of the story. Real Estate Economics, 26(3), 511-535. https://doi.org/10.1111/1540-6229.00755

Maitland-Smith, J., \& Brooks, C. (1999). Threshold autoregressive and Markov Switching models: an application to commercial real estate. Journal of Property Research, 16(1), 1-19. https://doi.org/10.1080/095999199368238

Maurer, R., Reiner, F., \& Sebastian, S. (2004). Characteristics of German real estate return distributions: evidence from Germany and comparison to the U.S. and U.K. Journal of Real Estate Portfolio Management, 10(1), 59-76. 
Miles, M., \& McCue, T. (1984). Commercial real estate returns. Journal of the American Real Estate and Urban Economics Association, 12(3), 335-377. https://doi.org/10.1111/1540-6229.00327

MSCI. (2017). MSCI real estate Solvency II 2017 update report. Retrieved from https://www.msci.com/ documents/10199/239004/MSCI+Real+Estate+Solvency+II+2017+Update+Report/136d5292c850-4485-b187-94b1218bc626

Myer, F. C. N., \& Webb, J. R. (1994). Statistical properties of returns: financial assets versus commercial real estate. Journal of Real Estate Finance and Economics, 8(3), 267-282. https://doi.org/10.1007/BF01096997

Quan, D. C., \& Quigley, J. M. (1989). Inferring an investment return series for real estate from observations on sales. Journal of the American Real Estate and Urban Economics Association, 17(2), 218-230. https://doi.org/10.1111/1540-6229.00487

Quan, D. C., \& Quigley, J. M. (1991). Price Formation and the appraisal function in real estate markets. Journal of Real Estate Finance and Economics, 4(2), 127-146. https://doi.org/10.1007/BF00173120

Schlumpf, F., Tessera, G., \& Martínez, C. (2013). Market risk of real estate: using indirect data to understand direct risks. Journal of Financial Perspectives, 1(3), 111-120.

Steffen, T. (2008). Solvency II and the work of CEIOPS. The Geneva Papers on Risk and Insurance - Issues and Practice, 33(1), 60-66. https://doi.org/10.1057/palgrave.gpp.2510162 